\title{
The Effectiveness of Mindfulness-Based Cognitive Group Therapy on Marital Satisfaction and General Health in Woman With Infertility
}

\author{
Najmeh Abedi Shargh ${ }^{1}$, Nour Mohammad Bakhshani ${ }^{2}$, Mohammad Davoud Mohebbi ${ }^{3}$, Khadije Mahmudian ${ }^{1}$, \\ Masood Ahovan ${ }^{4}$, Mojgan Mokhtari ${ }^{5} \&$ Alireza Gangali $^{2}$ \\ ${ }^{1}$ Health Promotion Research Center, Zahedan University of Medical Sciences, Zahedan, Iran \\ ${ }^{2}$ Children and Adolescents Research Center, Zahedan University of Medical Sciences, Zahedan, Iran \\ ${ }^{3}$ Department of Psychiatry, Zahedan University of Medical Sciences, Bahran Psychiatry Teaching Hospital, \\ Zahedan, Iran \\ ${ }^{4}$ Departmant of Counseling, Faculty of Psychology and Education, University of Allameh Tabatabai, Tehran, \\ Iran \\ ${ }^{5}$ Deptartment of Obstetrics and Gynecology, Faculty of Medicine, Zahedan University of Medical Sciences, \\ Zahedan, Iran
}

Correspondence: Najmeh Abedi Shargh, Health Promotion Research Center, Zahedan University of Medical Sciences, Zahedan, Iran. E-mail: abedishargh@hotmail.com

Received: March 12, 2015 Accepted: July 17, 2015 Online Published: August 6, 2015

doi:10.5539/gjhs.v8n3p230 URL: http://dx.doi.org/10.5539/gjhs.v8n3p230

\begin{abstract}
Infertility affects around 80 million people around the world and it has been estimated that psychological problems in infertile couples is within the range of $25-60 \%$. The purpose of this study was to determine the effectiveness of Mindfulness-based cognitive group therapy on consciousness regarding marital satisfaction and general health in woman with infertility. Recent work is a clinical trial with a pre/posttest plan for control group. Covering 60 women who were selected by in access method and arranged randomly in interference (30) and control (30) groups. Before and after implementation of independent variable, all subjects were measured in both groups using Enrich questionnaire and marital satisfaction questionnaire. Results of covariance analysis of posttest, after controlling the scores of pretest illustrated the meaningful difference of marital satisfaction and mental health scores in interference and control groups after treatment and the fact that MBCT treatment in infertile women revealed that this method has an appropriate contribution to improvement of marital satisfaction and mental health. Necessary trainings for infertile people through consultation services can improve their mental health and marital satisfaction and significantly help reducing infertile couples' problems.
\end{abstract}

Keywords: mindfulness, infertility, marital satisfaction, general health

\section{Introduction}

De Brardis (2014) in his studies entitled "Psychopathology, emotional aspects and psychological counseling in infertility: A review" demonstrated that infertility affects around 80 million people around the world and it has been estimated that psychological problems in infertile couples is within the range of $25-60 \%$. Depression and anxiety in infertile couples is considerably higher than fertile ones and the mental effect of this issue is higher in females compared to males. Psychological consultation can be a useful aid. A study performed by Tao (2012) revealed that male-based infertility has no negative contribution to marital factors. Moreover, infertile male participants expressed higher marital satisfaction from their wives, while females feel their marital relationship less stable and these factors include sexual satisfaction, age of couple, educational level and life quality. Results of various studies demonstrates that mental factors such as depression or anxiety can be a thread for outcome of treating infertility and By improving mental health, psychological treatments together with infertility treatment $o$ effectiveness of infertility treatments, encourage the infertile person to follow up the treatment as well (Shahrestani et al., 2012). Treatment recognition is defined based on the consciousness of someone regarding treatment process whose emphasis is over actively attending emotions and instantaneous thoughts of the patient without judging or evaluating that thought or feeling. After attention accompanied with consciousness, patient enters a strengthening situation made by him/herself and this trend finally leads to matching and improvement of 
thoughts and totally the quality of life (Younesi et al., 2008). In a study performed by Shahrestani et al. (2012) entitled effectiveness of group cognition therapy based on the consciousness in improvement of perceived stress dimensions and illogical cognitions in infertile women under IVF treatment, results demonstrated that cognition therapy based on consciousness is effective in improvement of illogical cognitions of parents and perceived stress of infertile women under IVF treatment. Results of Fili et al. (2012) corresponding to comparison of effectiveness of behavioral cognitions therapy and cognition therapy based on consciousness, revealed that by treatment methods can reduce rumination of infertile women. In a research performed by Galhardo et al. (2013), results demonstrated that women participating in Mindfulness plans based on plans until its end, showed a meaningful decrease in depression, exterior and interior shame, being trapped and failure. Furthermore, they had a considerable statistical improvement in concentration skills and self-efficiency in confronting infertility, in control group, there was no significant changes in psychological action except reduction of self-judgment. The purpose of this study was to the effectiveness of Mindfulness-based cognitive group therapy on Mindfulness regarding marital satisfaction and general health in woman with infertility.

\section{Materials and Methods}

Recent work is a clinical trial with a pre/posttest plan for control group. Studied community included all infertile women visiting female clinic of Ali Abitaleb hospital of Zahedan city in 2014 covering 60 women who were selected by in access method and arranged randomly in interference (30) and control (30) groups. Criteria for entering the study are as follows: recognition of infertility by obstetricians, minimum one year of recognition, being within the range of 20-45 years, minimum educational level of fifth grade of elementary school. Criteria for leaving the study were as follows: pregnancy before infertility recognition and psychological or drug treatments for mental or physical problem other than infertility. For interference group, the method of recognition therapy based on Mindfulness is applied according to the method described in reference book (Crane, 2009).

\subsection{The Contents of an 8-Session MBCT Program According to Crane's Book}

\subsubsection{First Week: Automatic Pilot}

Activities per session;

Mindful eating of a raisin;

Body scan meditation.

\subsubsection{Second Week: Removing Barriers}

Treatment with body scan meditation, ten minutes of breathing with mindfulness and meditation.

\subsubsection{Third Week: Mindfulness with Breathing (Body Movements Using This Technique)}

Conscious movement;

"Stretching and breathing exercises", maintaining the expansion of thoughts and the mind through following meditative practices and concentrating on conscious breathing and body parts. This practice might start with a short-time mindful thought, such as "seeing" or "listening".

\subsubsection{Fourth Week: Staying in the Present Moment}

5 minutes of seeing/listening to mindful-based cognitive method (awareness of breathing, body parts, sounds, thoughts and informed choices);

3 minutes of breathing- presenting patterned practices to be applied when experiencing uneasy feelings;

Mindful walking.

\subsubsection{Fifth Week: Acceptance and Allowance}

Meditation meetings with awareness of breathing and body parts. Putting emphasis on how to react to whatever we think and feel, and whatever originates from physical feelings. Creating a difficult condition for practice and discovering the effects of practices on mind and body;

3 minutes of breathing.

\subsubsection{Sixth Week: Thoughts are not Real}

Meditation meetings- Awareness of breathing and body- presenting patient problems during the practice, and discovering the effects of the practice on body and mind;

3 minutes of breathing. 


\subsubsection{Seventh Week: How Can We Best Take Care of Ourselves}

Meditation meetings- Awareness of breathing, body parts, sounds, thoughts and emotions;

3 minutes of breathing, presenting a problem during the practice and discovering its effect on body and mind.

\subsubsection{Eighth Week: How to Use These Points in Future Decisions}

Body scan meditation, end of treatment.

In this period, no psychological treatment was applied for control group. Before and after implementation of independent variable, all subjects were measured in both groups using Enrich questionnaire.

Marital satisfaction questionnaire (Olson et al., 1989) included 35 articles and 4 micro-scales of marital satisfaction, communications, conflict resolution and ideal deviation. In the study of Olson, Alpha coefficient of the questionnaire for micro-scales of marital satisfaction, communications, conflict resolution and ideal deviation is $0.74,0.78,0.61$ and 0.80 , respectively. The validity level of the tool through retest for micro-scales was 0.86 , $0.81,0.90$ and 0.92 , respectively.

General health questionnaire (GHQ-28): this questionnaire includes four micro-scales of body complaint, anxiety, depression and social malfunction. Yaghoubi (1995) reported the sensitivity of the test as much as 0.86 and its characteristic as 0.82 . This work also reports the general validity of the tests as much as 0.88 and validity of micro-scales within the range of 0.50-0.81.9 (Oraki et al., 2012).

\section{Results}

In this section, demographic characteristics are described using the frequency and percentage indices. The subjects' demographic characteristics are shown in table 1.

As seen in Table 1, the age range of the samples was as follows: 15 (25\%) were 20-28, 38 (63.33\%) were 29-37, and $7(11.66 \%)$ were $38-45$. In terms of the duration of infertility, $12(20 \%)$ have been infertile for 1-3 years, 42 $(70 \%)$ for $4-7$ years, and $6(10 \%)$ for $8-10$ years. The highest percentage of the duration of infertility was therefore $4-7$ years. In terms of education level, more than half of the participants $(53.33 \%)$ held a fifth grade elementary school degree.

Table 1. The frequency distribution of infertile women according to some demographic features

\begin{tabular}{llll}
\hline Variable & Range & Frequency & Percent \\
\hline \multirow{3}{*}{ Age (year) } & $20-28$ & 15 & 25 \\
& $29-37$ & 38 & 63.33 \\
& $38-45$ & 7 & 11.66 \\
\cline { 2 - 4 } Duration of infertility(year) & $1-3$ & 12 & 20 \\
& $4-7$ & 42 & 70 \\
& $8-10$ & 6 & 10 \\
\cline { 2 - 4 } Education level & Elementary & 32 & 53.33 \\
& Secondary & 13 & 21.66 \\
& Diploma & 10 & 16.66 \\
& Bachelor's degree & 5 & 8.33 \\
\hline
\end{tabular}

Table 2 shows the moderate averages; that is, the effect of random variable is eliminated statistically.

Average of interference group for the variable of marital satisfaction is as much as 1.154 while this is 1.07 for control group which shows the improvement of marital satisfaction of interference group after treatment. Average of moderated scores of mental health in control group and interference group was 55.09 and 45.306, respectively which demonstrates the improvement of average scores in interference group after treatment. 
Table 2. Estimated Marginal Means group (Dependent Variable: posttest)

\begin{tabular}{llllll}
\hline & group & Mean & Std. Error & & \multicolumn{2}{c}{ 95\% Confidence Interval } \\
\cline { 5 - 6 } & & & & Lower Bound & Upper Bound \\
\hline \multirow{2}{*}{ Marital satisfaction } & Interference & $1.154 \mathrm{E} 2^{\mathrm{a}}$ & 2.762 & 109.833 & 120.898 \\
& Control & $1.070 \mathrm{E} 2^{\mathrm{a}}$ & 2.762 & 101.423 & 112.488 \\
\cline { 2 - 5 } Mental health & Interference & $55.094^{\mathrm{b}}$ & 2.116 & 50.856 & 59.331 \\
& Control & $45.306^{\mathrm{b}}$ & 2.116 & 41.069 & 49.544 \\
\hline
\end{tabular}

a. Covariates appearing in the model are evaluated at the following values: Marital satisfaction $=97.6833$.

b. Covariates appearing in the model are evaluated at the following values: Mental health $=41.6500$.

Results of investigation of statistical presumptions revealed that both presumptions of equality of variances and normality are applicable $(\mathrm{p}<0.05)$. Results of covariance analysis of posttest, after controlling the scores of pretest illustrated the meaningful difference of marital satisfaction and mental health scores in interference and control groups after treatment and the fact that women have higher marital satisfaction and mental health after applying independent variable (Table 3).

Table 3. Summary of results from ANCOVA of variance related to score Mean of marital satisfaction and mental health

\begin{tabular}{lllllllll} 
health & \multicolumn{1}{c}{ post } & & test \\
\hline \multirow{2}{*}{ Marital satisfaction } & source & Sum of Squares & df & Mean Square & F & Sig & Partial Eta Squared \\
& Pretest & 5658.905 & 1 & 5658.905 & 22.885 & .000 & .286 \\
\multirow{3}{*}{ Mental health } & group & 1060.956 & 1 & 1060.956 & 4.291 & .043 & .070 \\
& Pretest & 4731.948 & 1 & 4731.948 & 35.224 & .000 & .382 \\
& group & 1436.348 & 1 & 1436.348 & 10.692 & .002 & .158 \\
\hline
\end{tabular}

\section{Discussion and Conclusion}

Results of MBCT treatment in infertile women revealed that this method has an appropriate contribution to improvement of marital satisfaction which was compatible with similar works. Stress of infertility is correlated to the reduction of marital satisfaction (Gana et al., 2014; Rockliff et al., 2014; Mosalanejad et al., 2014; Cserepes et al., 2013; Tao et al., 2012). Mindfulness is sometimes related to romantic relations (Barnes et al., 2007). Furthermore, infertility consultation improves sexual and marital satisfaction in infertile couples (Vizheh et.al, 2013). There is a positive relationship between Mindfulness and marital satisfaction and Mindfulness skills may lead to marital satisfaction (OmidBeiki et al., 2014). Carson et al. (2004) showed that Mindfulness treatment improves marital satisfaction. It must be noted that this compatibility may be the result of MBCT treatment characteristics since with regard to MBCT, it is always implied that this strategy is appropriate for those who are depressed, anxious or are not martially satisfied. In study of the second hypothesis, research findings revealed that women treated by MBCT, have meaningfully different mental health from those who are not treated by this treatment method. This means that MCBT treatment is effective in improving mental health of infertile women of Zahedan. This results are in agreement with that of Galhardo et al. (2013); Shahrestani et al., 012); Fili et al. (2012). Infertility is one of the factors which lead to lower mental health (Hasanpour et al., 2014; Baghianimoghadam et al. 2013; Ahmadi Forooshany et al., 2012; Peterson et al., 2003). Sherratt et al., (2013) showed that MBCT treatment is effective in reducing infertility-related psychological problems and will result in higher wellbeing scores and psychological distress. Research shows that Mindfulness leads to improvement of mental health (Pots et al., 2014; Tran et al., 2014; Caldwell et al., 2014). In explaining the reason of the effectiveness of MCBT in improving psychological health of infertile women, it can be said that one of the factors resulting in reduction of mental health of infertile women, is daily life stresses and social pressures. Therefore, it seems that MBCT can help people recognize situations which lead to stress and sadness and apply MBCT strategies to confront them. Another explanation for the effectiveness of the aforesaid interference is mental support which leads to the change of vision of infertile women toward themselves. They no longer feel loneliness nor consider their problem as unique and get an environment in which they are able to address their feelings and problems. 
Researches prove the mental inconveniences such as anxiety, depression and mental disturbances. Necessary trainings for infertile people through consultation services can improve their mental health and marital satisfaction and significantly help reducing infertile couples' problems. In fact, the MBCT exercises seem to be effective in the cognitive system and information processing as people become more aware of the present time through techniques such as paying attention to breathing and body and concentrating on here and now. A widespread application of this technique is therefore recommended, given that this type of education is effective and this technique is beneficial in the considered domains. Based on the findings of the present study and considering the effectiveness of MBCT training, a continuous MBCT usage can be suggested to improve the participants' life and reduce their problems.

Marital satisfaction is a variable influenced by the characteristics of both men and women. Due to men's lack of cooperation and sometimes not being accompanied by women, only the female sample was used. It is suggested that their husbands also be studied by coordinating the families better in future studies. Some other studies are also suggested to be performed on samples with different types of infertility dividing them according to their gender, and study the effect of demographic variables such as age, education, income, and job on infertility levels and types of problems caused by it.

\section{Acknowledgements}

This study is a part of a master thesis whith $82 / \mathrm{k}$ number which had been done at the Zahedan University of Medical Sciences.

\section{Conflict of Interest}

The authors declare no conflict of interest in this study.

\section{References}

Ahmadi Forooshany, S. H., Yazdkhasti, F., Safari Hajataghaie, S., \& Nasr Esfahani, M. H. (2014). Infertile individuals' marital relationship status, happiness, and mental health: A causal model. Int J Fertil Steril., $8(3), 315-24$.

Baghianimoghadam, M. H., Aminian, A. H., Baghianimoghadam, B., Ghasemi, N., Abdoli, A. M., Seighal Ardakani, N., \& Fallahzadeh, H. (2013). Mental health status of infertile couples based on treatment outcome. Iran J Reprod Med., 11(6), 503-10.

Barnes, S., Brown, K. W., Krusemark, E., Campbell, W. K., \& Rogge, R. D. (2007). The role of mindfulness in romantic relationship satisfaction and responses to relationship stress. J Marital Family Therapy, 33(4), 482-500. http://dx.doi.org/10.1111/j.1752-0606.2007.00033.x

Caldwell, K., Adams, M., Quin, R., Harrison, M., \& Greeson, J. (2013). Pilates, Mindfulness and Somatic Education, Bibliotherapy to decrease stress and anxiety and increase resilience and mindfulness: A pilot trial. Dance Somat Pract, 5(2), 141-53. http://dx.doi.org/10.1386/jdsp.5.2.141_1

Carson, J. W., Carson, K. M., Gil, K. M., \& Baucom, D. H. (2004). Mindfulness-based relationship enhancement. Behavior Therapy, 35(3), 471-494. http://dx.doi.org/10.1016/S0005-7894(04)80028-5

Crane, R. (2009). Mindfulness based cognitive therapy (1st ed.). New York: Rout ledge press.

Cserepes, R. E., Kollár, J., Sápy, T., Wischmann, T., \& Bugán, A. (2013). Effects of gender roles, child wish motives, subjective well-being, and marital adjustment on infertility-related stress: a preliminary study with a Hungarian sample of involuntary childless men and women. Arch Gynecol Obstet, 288(4), 925-932. http://dx.doi.org/10.1007/s00404-013-2835-7

De Berardis, D., Mazza, M., Marini, S., Del Nibletto, L., Serroni, N., Pino, M. C., et al. (2014). Psychopathology, emotional aspects and psychological counseling in infertility: A review. Clin Ter, 165(3),163-9.

Feili, A. R., Borjali, A., Sohrabi, F., \& Arrokhi, N. (2011). The Comparative efficacy of Cognitive -Behavior Therapy and Teasdale Mindfulness-Based Cognitive Therapy of Infertile Depressed Women's Rumination. Armaghan-Danesh, 17(1), 14-21.

Galhardo, A., Cunha, M., \& Pinto-Gouveia, J. (2013). Mindfulness-Based Program for Infertility: efficacy study. Fertility and Sterility, 100(4), 1059-1067. http://dx.doi.org/10.1016/j.fertnstert.2013.05.036

Gana, K., \& Jakubowska, S. (2014). Relationship between infertility-related stress and emotional distress and marital satisfaction. Health Psychol. 19. pii: 1359105314544990. http://dx.doi.org/10.1177/1359105314544990 
Hasanpour, S., Bani, S., Mirghafourvand, M., \& Yahyavi Kochaksarayie, F. (2014). Mental health and its personal and social predictors in infertile women. J Caring Sci., 3(1), 37-45.

Mosalanejad, L., Parandavar, N., Gholami, M., \& Abdollahifard, S. (2014). Increasing and decreasing factors of hope in infertile women with failure in infertility treatment: A phenomenology study. Iran J Reprod Med, 12(2), 117-24.

Fowers, B. J., \& Olson, D. H. (1989). Enrich Marital Inventory: A Discriminant Validity And Cross-Validation Assessment. Journal of Marital and Family Therapy, 15(1), 65-79. http://dx.doi.org/10.1111/j.1752-0606.1989.tb00777.x

Omidbeiki, M., Khalili, S. H., Gholamali Lavasani, M., \& Ghorbani, N. (2014). The Relationship between Mindfulness and Integrative Self- Knowledge with Marital Satisfaction. Journal of Psychology, 18(3), 327-341.

Oraki, M., Bayat, S. H., \& Khodadust, S. (2012). Study of Effectiveness Mindfulness Cognitive Therapy and Marlaat Relapse Preventive Intervention for Mental Health in Male Crack Addictions. Health Psychology 1, $22-30$.

Peterson, B. D., Newton, C. R., \& Rosen, K. H. (2003). Examining congruence between partner's perceived infertility-related stress and its relationship to marital adjustment and depression in infertile couples. Family Process, 42(1), 59-70. http://dx.doi.org/10.1111/j.1545-5300.2003.00059.x

Pots, W. T. M., Meulenbeek, P. A. M., Veehof, M. M., Klungers, J., \& Bohlmeijer, E. T. (2014). The Efficacy of Mindfulness-Based Cognitive Therapy as a Public Mental Health Intervention for Adults with Mild to Moderate Depressive Symptomatology: A Randomized Controlled Trial. PLoS ONE, 9(10), e109789. http://dx.doi.org/10.1371/journal.pone.0109789

Rockliff, H. E., Lightman, S. L., Rhidian, E., Buchanan, H., Gordon, U., \& Vedhara, K. (2014). A systematic review of psychosocial factors associated with emotional adjustment in in vitro fertilization patients. Human Reproduction Update, 20(4), 594-613. http://dx.doi.org/10.1093/humupd/dmu010

Shahrestani, M., Ghanbari, B., Nemati, S., \& Rahbardar, H. (2012). Effectiveness of Mindfulness-based cognitive group therapy on improvement of perceived stress of infertility and irrational cognitions in infertile women undergoing IVF. Obstetrics Gynecology and Infertility, 59, 28.

Sherratt, K. A. L., \& Lunn, S. (2013). Evaluation of a group programme of mindfulness-based cognitive therapy for women with fertility problems. Journal of Obstetrics \& Gynaecology, 33(5), 499-501. http://dx.doi.org/10.3109/01443615.2013.786031

Tao, P., Coates, R., \& Maycock, B. J. (2012). Investigating marital relationship in infertility: a systematic review of quantitative studies. Reprod Infertil, 13(2), 71-80.

Tran, U. S., Cebolla, A., Glück, T. M., Soler, J., Garcia-Campayo, J., \& von Moy, T. (2014). The Serenity of the Meditating Mind: A Cross-Cultural Psychometric Study on a Two-Factor Higher Order Structure of Mindfulness, Its Effects, and Mechanisms Related to Mental Health among Experienced Meditators. PLoS ONE, 9(10), e110192. http://dx.doi.org/10.1371/journal.pone.0110192

Vizheh, M., Pakgohar, M., Babaei, G., \& Ramezanzadeh, F. (2012). Effect of counseling on quality of marital relationship of infertile couples: a randomized, controlled trial (RCT) study. Arch Gynecol Obstet, 287(3), 583-589. http://dx.doi.org/10.1007/s00404-012-2595-9

\section{Copyrights}

Copyright for this article is retained by the author(s), with first publication rights granted to the journal.

This is an open-access article distributed under the terms and conditions of the Creative Commons Attribution license (http://creativecommons.org/licenses/by/3.0/). 